\title{
EXCHANGE IN LEVI-STRAUSS'S THEORY OF SOCIAL ORGANIZATION*
}

\author{
Harland Prechel \\ University of Kansas
}

Mid-American Review of Sociology, 1980, Vol. V, No. 1:55-66

\section{INTRODUCTION}

This paper explicates the role of exchange in Levi-Strauss's theory of social organization, and integrates it into his general problematic. It focuses primarily on the original works of Claude Levi-Strauss, but also incorporates and critically reviews certain aspects of Ekeh (1974) and Turner (1974). Although Levi-Strauss is an anthropologist, his theoretical insights can be especially useful to the sociologist interested in macrosociology.

To properly understand Levi-Strauss's notion of social organization and the role exchange plays in his theory, LeviStrauss should be set in the proper intellectual tradition. There are "two distinct traditions of social exchange theory, the "collectivistic' [theories of] Levi-Strauss .... and the 'individualistic' [perspective of] Homans" (Ekeh, 1974:5). Homans's theory developed from the British utilitarian tradition and focuses on interaction between individuals. Levi-Strauss, on the other hand, emerges from the French-Durkheimian tradition, which emphasizes society as a collectivity. Like Durkheim, Levi-Strauss is concerned with the integration and organization of society. In Levi-Strauss's work, exchange plays a similar role in the theory of social organization as the division of labor does in Durkheim's theory.

Although Ekeh correctly observes the existence of two major theoretical traditions in exchange theory and accurately describes most aspects of Levi-Strauss's theory, he and Turner

\footnotetext{
* I thank Gary Nigel Howe for his organizational and substantive criticisms on the various draft of this paper.
} 


\section{Mid-American Review of Sociology}

fail to properly understand Levi-Strauss's problematic, leading them to a serious mistake in their final analysis. In fact, the secondary literature as a whole has failed to properly connect Levi-Strauss's social exchange theory with the organization of society and has misunderstood his problematic. The problematic as used by the French structuralists:

is a particular way of looking at the world, defined by the fundamental question asked, ... which includes concepts, methods, and theories. To isolate a problematic requires more than a simple reading of the text, but depends on making explicit concepts that are often only latent, and investigating their interrelationship within the total system.

The notion of the problematic thus provides us with a guiding question around which to orientate our study, ... (Glucksmann, 1974:47).

This definition of a problematic is distinctly different than the common usage of the term, in which "problematic" means difficult to solve or understand. For the French structuralist, problematic refers to the dominant or essential elements of a theory: that is, the dominant concepts and the relationship among them. Because of the style and organization of Levi-Strauss's writing, to discover his problematic, the essential structure of his thought, is not a particularly easy task. His style is full of ambiguities, double meanings, and as a consequence:

the meaning of his writing does not necessarily reside in the chronological succession of words and chapters[:] the reader has to undertake what Althusser calls a 'lecture symptomale,' trying to fit together the various threads and themes so as to discover their underlying relationship (Glucksmann, 1974:47).

His mode of expression often confuses rather than clarifies the issues he is expounding on. Levi-Strauss "tries to make a reading of his work as difficult for the reader as the deciphering of myth was for himself" (Glucksmann, 1974:47.). The purpose of his obfuscated style, which may on the surface appear to be an exercise in intellectual arrogance, is to mirror "the essential
Exchange in Levi-Strauss

ambiguity of meanings or levels of signification inherent in what is being examined" (Glucksmann, 1974:48). Unless Levi-Strauss's method is properly understood it is impossible to understand his problematic.

Levi-Strauss's problematic is: how is society possible? To determine how society is possible we must determine the role of exchange in the various societies with which Levi-Strauss was concerned. It is important to demonstrate that Levi-Strauss was concerned with the social organization of societies in general, not just primitive societies. I disagree here with Ekeh and others who maintain that: "Levi-Strauss regard[s] economic motives as unimportant in social exchange and reject[s] the assumptions of the Economic Man in social exchange theory" (Ekeh, 1974:200). Ekeh fails because he misunderstands Levi-Strauss's problematic, which leads him to look solely at Levi-Strauss's work on primitive society and ignore his theory of modern society. I will now attempt to unravel the threads and themes of Levi-Strauss's problematic, and delineate a coherent theory of how social exchange integrates and organizes both primitive and modern societies.

\section{TOTEMIC SOCIETY}

According to Levi-Strauss, totemic societies exist because the members of those societies draw analogies between themselves and the differentiations that exist in nature. Man has no physical distinctions to differentiate himself from other men. He perceives physical distinctions in nature, and superimposes these distinctions upon himself to create a basis for society. Primitive man uses plants and animals in totems and myth as a tool to organize social relations through analogies with the physical world. It is not that members of the Beaver clan look, or live like Beavers, while those of the Eagle clan look, or live like Eagles. Rather, as animals differ from one another, clans do so analogously. Totemism is a system that exemplifies these analogical differences between groups of men and groups of plants or animals. LeviStrauss proposes that the primitive names his clan after an eagle 
or beaver because they are appropriate vehicles for capturing the perceptual distinctions that have impressed themselves on the individual or group. These perceptual distinctions are the means primitive man uses to organize cultural life. Society is possible because of the "naturalization" of man, who creates artificial distinctions by applying to himself those distinctions he sees in nature. The natural model is a functional necessity for society. It guides the creation of artificial distinctions between [men]: "[Man] comes to acquire the capacity to distinguish himself as he distinguishes them, i.e., to use diversity of species as conceptual support for differentiation" (Levi-Strauss, 1963:101). Men, in primitive societies, differ from other men only at the cultural level of their existence. This differentiation is determined by distinctions in nature that are applied to groups of men. Totemism is the mechanism that exhibits these distinctions drawn from nature and applied to culture.

For Levi-Strauss, homologies are the structural similarities between nature and culture that primitive man perceives. Primitive man uses the nature-culture dichotomy in the form of totems as a methodological device to bring social organization to his environment. Interpreted in the context of nature, totems exhibit relationships among various species of plants and animals. If we instead give totems a cultural interpretation-apply these relationships to people-we have a basis for the organization of society. Perceiving this homologous method gives an understanding of the structure of society, and the social relationships between those people identifying themselves with the totem. Totems exhibit homologies between two systems, one occurring in nature and the other in culture: "Totemism is based on a postulation of homology between two parallel series-that of natural species and that of social groups..." (Levi-Strauss, 1966:224). Prior to the application of nature to make distinctions between men, culture or society did not exist, nor was it possible. Totemism served as a mechansim and constant reminder enabling man to distinguish himself from other men. Prior to the application of nature to culture man's environment was chaotic because it lacked diversity. Natural distinctions were used to illustrate social relations because they are "good to think" (Levi-Strauss,
1963:89). The natural distinctions perceived in nature and applied to culture form the foundation of a conceptual diversity that makes social integration and organization possible.

For Levi-Strauss exchange systems unify the various cultural groups created by totemism. In totemic societies "both the exchange of women and the exchange of food are means of securing or displaying the interlocking of social groups with one another" (Levi-Strauss, 1966:109). But the function of exchange is not restricted to the group level; it also serves to bind individuals together: "The exchange of gifts (taking place on the occasion of a periodic settlement of grievances between the groups) ... is not a business of transaction-not a mere bartering-but a means of expressing and cementing friendship" (Levi-Strauss, 1969:114). The differences man sees in nature and applies to culture create artificial distinctions between men. These artificial distinctions are a means for man to differentiate himself from other men. The system of exchange in totemic society establishes a basis for social organization by providing links between men. Marriage systems institutionalize these links:

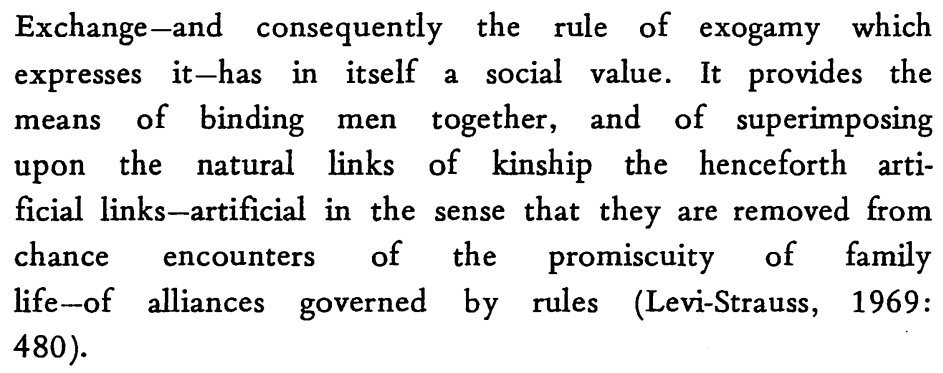
upon the natural links of kinship the henceforth artificial links-artificial in the sense that they are removed from chance encounters of the promiscuity of family life-of alliances governed by rules (Levi-Strauss, 1969: 480).

Furthermore, systems of exchange have the power of "integrat [ing], within one and the same social structure, ... ethically and geographically remote groups" (Levi-Strauss, 1969:289). It is here that Turner confuses the role of exchange in Levi-Strauss. Turner (1974:221) states that “. . . these exchange processes are caused by patterns of social integration and organization...." For Levi-Strauss, the process is precisely the opposite: Social integration and organization occur as a result of exchange systems. Within exogamous marriage systems, exchange functions to unify society. 


\section{EXOGAMY}

Exogamous marriage systems function as a "means of securing or displaying the interlocking of social groups with one another" (Levi-Strauss, 1966:109). The exchange systems of exogamy provide a means to develop social relations with other groups, which are necessary for the organization of society. These social relations help provide and maintain a communications system between neighboring tribes that facilitates military organization against a common enemy, provides food during famines, guarantees the safety of travelers in neighboring villages, and brings leaders together to outline territories and settle disputes.

We know what function is fulfilled by the incest prohibition in primitive societies. By casting, so to speak, the sisters and daughters out of the consanguine group, and by assigning to them husbands coming from other groups, the prohibition creates bonds of alliance between these natural groups, the first ones which can be called social. The incest prohibition is thus the basis of human society: in a sense it is society (Levi-Strauss, 1976:19).

The exchange system created by exogamy is the core of LeviStrauss's problematic. Exogamy provides a system of exchange between various groups, and it is this exchange system that makes society possible. The marriage system determines the superstructure of those societies and provides social solidarity.

Social groups are distinguished from one another but they retain their solidarity as parts of the same whole, and the rule of exogamy furnishes the means of resolving this opposition balanced between diversity and unity (Levi-Strauss, 1966:116).

As long as society maintains this reciprocal exchange between groups, they are locked into a permanent superstructure that insures their solidarity. When exogamous kinship systems begin to break down:
Exchange in Levi-Strauss

Each social group ....tend[s] to form a system no longer with other social groups but with particular differentiating properties regarded as hereditary, and these characteristics exclusive to each group will weaken the framework of solidarity within the society (Levi-Strauss, 1966:116).

The transition from an emphasis on differentiation between groups to differentiation between individuals begins to break down solidarity. This new system of differentiation, according to Levi-Strauss, is based on economic criteria and occurs in caste societies.

It is important to interject at this point that Levi-Strauss's concepts are ideal types. He associates endogenous marriage systems with caste societies and exogenous marriage systems with totemic societies. He is aware that many primitive societies have a combination of endogenous and exogamous marriage systems; the more closely a society represents the ideal type exogamous marriage system (in totemic society), the greater the social solidarity. When caste systems develop and exchange is no longer based on exogamous marriage, social solidarity begins to break down. Exchange, in caste societies, takes on an entirely different function and establishes a different basis for social organization. It is within the context of caste society that Levi-Strauss develops his notion of Economic Man that Ekeh and others have ignored. The transition from an exogamous to an endogenous marriage system paves the way for the organization of modern society.

\section{CASTE SOCIETY}

Within the theoretical framework of Levi-Strauss, caste and class societies are synonomous; both use economic criteria to differentiate between individuals. Although Levi-Strauss focuses primarily on primitive (totemic) societies, he has a clear conception of modern (caste) societies. The endogenous systems of caste society no longer exchange women to link various groups together. This transition not only reduces social solidarity, but 


\section{Mid-American Review of Sociology}

drastically alters the role of exchange and the basis of differentiation within society. Instead of linking groups or clans with one another, exchange in caste societies distinguishes individual men from one another.

The exchange of manufactured objects rather than women characterizes caste societies. This distinction has important ramifications for society:

Women are biological individuals...naturally procreated by other biological individuals. Goods and services on the other hand are manufactured objects,...that is, social products culturally manufactured by technical agents (Levi-Strauss, 1966: 123).

Both exchange systems promote the organization and integration of society, but this is the extent of their similarity. The two systems operate with completely different criteria. The exchange of women, who represent different species in nature, serves to bring together groups that appear as different from one another. The manufacture of items provides a means to differentiate between men on the basis of their particular occupational specializations. Because of this transition artificial distinctions drawn from nature and applied to men are no longer necessary as a means of differentiation. The creation of the division of labor provides a means to differentiate men and groups of men from one another.

The first level of differentiation occurs "on the cultural plane by the diversity of functions" (Levi-Strauss, 1966:124). A second level of differentiation develops with the emergence of Economic Man. This differentiation can be explained best in the context of Levi-Strauss's concepts of hot and cold socieites.

\section{HOT AND COLD SOCIETIES}

Levi-Strauss's distinction between totemic and caste societies is synonomous with his distinctions between exogamy and endogamy, and hot and cold societies. That is, cold societies have totemic and exogamous systems, while hot societies have caste and endogamous systems. Although Levi-Strauss uses the concepts of exogamy and endogamy, totems and castes, cold and hot societies, he readily admits that "there is probably no concrete society which, in its whole as well as its components correspond exactly to [any of these types]" (Levi-Strauss, 1976:29; 1966: 118). Cold societies are characterized by a permanent structure of exogamous exchange relations, which are necessary for the maintenance of these societies. According to Levi-Strauss's scheme, a society that deviates from this structure will disintegrate or necessarily become a caste society. Cold societies are guided by the institutions they develop and history has little impact on their development. In cold societies the natural and human counterparts:

exist in time but under an atemporal regime, since, being both real they sail through time together, remaining such as they were at the moment of separation. The original series [nature] is always there, ready to serve as a system of reference for the interpretation and rectification of the changes taking place in the derivative series [human society]. In theory, if not in practice history is subordinate to system (Levi-Strauss, 1966:233).

The institutions of exogamy and totemism unify, guide and integrate cold societies, and contribute to the organization of a permanent superstructure.

In a word, these societies, which we might define as 'cold' because their internal environment borders on the zero of historical temperature, are distinguished by the limited number of people and their mechancial mode of functioning from the 'hot' societies which appeared in different parts of the world following the Neolithic revolution. In the latter, differentiations between castes and classes are emphasized unceasingly in order to draw from them change and energy (Levi-Strauss, 1976:29).

In hot (caste) societies, distinctions are made on the basis of manufactured items, change becomes a part of these societies, and Economic Man emerges. 
As Economic Man emerges so does economic differentiation among men. In cold societies exchange was based on the need for kinship ties, shelter in unfamiliar territory, etc., whereas in hot societies the basis of exchange is economic. Under these conditions, castes and classes emerge, artificial distinctions disappear and economic distinctions replace them. In a society based on economic organization artificial distinctions are no longer needed because real-life distinctions now exist. Economic factors become the driving forces in society, change occurs, and historical processes develop, replacing an atemporal regime. Change, according to Levi-Strauss, is a result of a system of economic exchange relations. Growth and expansion become the dominant ideology in societies based on an economic system: as a consequence the superstructure in hot societies constantly changes.

Levi-Strauss uses the Neolithic and industrial revolutions to illustrate the impact of history. The rapid change that resulted from these revolutions significantly contributed to the shift toward economic differentiation as a basis of social organization, which reaches its highest level of development in modern capitalist society.

... [T] he Neolithic and industrial [revolutions], came along with not only a diversification of the social body but also the institution of contrasting statuses among the group, especially from the economic point of view. We have long observed that the Neolithic discoveries quickly led to social differentiation, with the emergence in the ancient Orient of great urban concentrations and the appearance of states, castes, and classes. The same observation can be made about the Industrial Revolution, conditioned by the appearance of a proletariat and leading to new and more advanced forms of exploitation of human labor (Levi-Strauss, 1976:359).

Levi-Strauss does not restrict himself to these illustrations, but maintains that a series of historical factors including the development of the Mediterranean city-states and mercantile capitalism also contribute to this progression. Economic growth and an emphasis on expansion bring progress and change. The structure and organization of society is increasingly dictated by economic criteria. Social organization is no longer determined by exchange relations between groups, but by exchange relations between individuals and their positions in the division of labor. In capitalist society, where there is an increased emphasis on production and consumption, change and inequality become an inevitable feature. For Levi-Strauss superstructure is the key to understanding social organization, and it is toward a "theory of superstructure" (1966:139) that he hopes to make a contribution.

\section{SUMMARY AND CONCLUSION}

The superstructure that was once based on institutionalized exchange relations between groups of men is in modern society based on the mode of production. For illustrative purposes this notion of Levi-Strauss's can be compared to Marx's conception of the subject-object inversion (Marx, n.d.:76-87). In cold society, man as subject determines the social organization of society through the application of the nature-culture dichotomy and exchange relations; in hot society, man's creation, the capitalist mode of production, becomes the subject determining distinctions and relations between men, reducing man to the object. The role of exchange in these two types of societies is essential to understanding this inversion. In cold societies man draws analogies between nature and culture and uses them to create artificial distinctions among men. Exchange relations are established to provide links between men and serve as a basis for social organization.

According to Levi-Strauss, exchange serves an entirely different function in hot societies. Exchange creates real economic distinctions that provide a basis of differentiation between men, thus defining social relations and the structure of society. Because social relations in hot societies obtain an objective economic bases, artificial distinctions created by the nature-culture dichotomy are not necessary for social organization. Instead of institutionalizing marriage and kinship systems to organize society, the mode of production becomes the principle of organization 


\section{Mid-American Review of Sociology}

and man acts within the realm of possibilities the productive system provides. In primitive society man applied distinctions he perceived in nature to himself as a means to create artificial distinctions between men and provide a basis of social organization. In modern societies the mode of production and the system of exchange creates economic inequalities that create real distinctions between men. These distinctions are used as a basis to define social relations and the structure of society. Whereas primitive man determined the superstructure, and exchange provided a system to link men together, the superstructure in modern societies is determined by the mode of production. Economic inequalities created by the system of exchange are used to differentiate among men.

Differentiation and exchange serve as the bases of social cohesion in both types of society, but obey entirely different "historical logics." The totemic society is stablized by an artificial homology with nature, whereby man becomes subject through the application of natural objectivity. In caste society production for exchange becomes the center of the system, but only at the expense of displacing men from their determinative role as the subject of history.

\section{REFERENCES}

Ekeh, Peter P.

1974 Social Exchange Theory. London and Edinburgh: Morrison and Gibb Ltd.

Glucksmann, Miriam

1974 Structuralist Analysis in Contemporary Social Thought. London and Boston: Routledge and Kegan Paul.

Levi-Strauss, Claude

1963 Totemism. Boston: Beacon Press.

1966 The Savage Mind. Chicago: The University of Chicago Press.

1969 The Elementary Structure of Kinship. London: Eyre and Spottiswoode.

1976 Structural Anthropology Vol. II. New York: Basic Books.

Marx, Karl

n.d. Capital Vol. I. Moscow: Progress Publishers.

Turner, Jonathan $H$.

1974 The Structure of Sociological Theory. Homewood, Illinois: The Dorsey Press.

\section{NOTES AND COMMENTS}

\section{"WHY DOESN'T HE MENTION SO-AND-SO?”}

Martin E. Spencer

State University College of New York at Oneonta

It is especially telling, I think, that a chapter entitled 'Responses to Death and Stages of Grieving' could be written without reference to either Freud or Erich Lindemann. Or, as another example, chapter 4 (a rather peculiar section, reviewing some of the various 'contexts' in which death occurs, i.e., homicide, disease, accident, etc.) manages to discuss situations of mass death in war and natural disaster without so much as a nod in the direction of Robert Lifton (Lofland, 1979).

The above is a typical specimen of the genre of academic comment that I shall refer to here as "why doesn't he mention so-and-so?" Taken at face value, the purpose of such remarks is to set straight a piece of unsound academic business. But, I shall argue, the tone of righteous intellectual indignation that appears in comments of this order is misplaced, because what they really signify is a profound "epistemological pathology" of the social sciences. On the deepest level of its consequences, this pathology condemns the social sciences to a collective existence characterized by the profitless rise and fall of mutually hostile and exclusive schools of thought.

As an index of this pathology, I shall focus on the use of citations in social science, a use that is generally, as concerns its rationale, "taken-for-granted." For our purposes, let us initially consider citations in the broad category of "primary" and "secondary" citations. The first concerns the use of "data" or "evidence," and their purpose appears to be the documentation of such "evidence," i.e., the rooting of the arguments in the "facts" of social reality. I shall consider citations of this order in due course, but, for the moment, let us focus on the "secondary citations." These are citations that refer, not to the "data," "evidence," or 